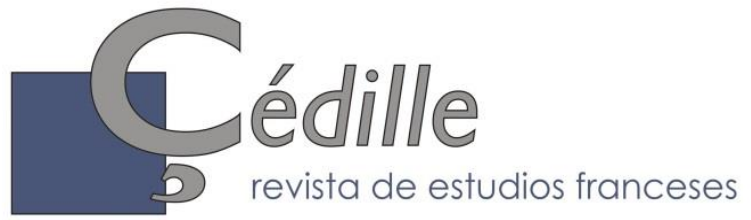

\title{
La condición órfica en la narración maravillosa: tres cuentos de Perrault
}

\author{
Ethel JunCO Claudio César CALABRESE \\ Universidad Panamericana (México) \\ ejunco@up.edu.mx_ccalabrese@up.edu.mx
}

\section{Resumen}

En este artículo nos ocupamos del tópico de la condición, según está presente en el mito del descenso al Hades de Orfeo en busca de Eurídice, en tres cuentos de Charles Perrault. A través de este tópico, indagamos la naturaleza de la condición originaria así como las transformaciones de los personajes que la ejecutan o que la sufren. Destacamos que los cuentos de hadas recrean los ejes de mito, música, muerte y amor, y manifiestan una visión del mundo en la que predomina la idea de anábasis y renacimiento a partir de la premisa del autoconocimiento. Concluimos que el motivo mítico articula los cuentos como un intertexto, aun cuando las variantes del autor modifiquen trama y relaciones.

Palabras clave: Mito. Cuento de hadas. Orfeo. Perrault. Prueba. Autoconocimiento.

Abstract

In this article we deal with the topic of the condition, as it is present in the myth of the descent into Hades of Orpheus in search of Eurydice, in three stories by Charles Perrault. Through this topic, we investigate the nature of the original condition as well as the transformations of the characters that execute it or that suffer it. We emphasize that fairy tales recreate the axes of myth, music, death and love, and manifest a vision of the world in which the idea of anabasis and rebirth predominates based on the premise of self-knowledge. We conclude that the mythical motive articulates the stories as an intertext, even when the variants of the author modify plot and relationships.

Keywords: Myth. Fairy tale. Orpheus. Perrault. Condition. Self-knowledge.

Résumé

Dans cet article, nous traitons du motif de la condition, tel qu'il est présent dans le mythe de la descente dans l' Hadès d'Orphée à la recherche d'Eurydice, dans trois contes de Charles Perrault. À travers cette rubrique, nous étudions la nature de la condition d'origine ainsi que les transformations des personnages qui l'exécutent ou qui en souffrent. Nous soulignons que les contes de fées recréent les axes du mythe, de la musique, de la mort et de l'amour, et manifestent une vision du monde dans laquelle l'idée d'anabasis et de renaissance

* Artículo recibido el 22/07/2019, aceptado el 4/11/2019. 
prédomine sur la base de la connaissance de soi. Nous concluons que le motif mythique articule les histoires comme un intertexte, même lorsque les variantes de l'auteur modifient l'intrigue et les relations.

Mots clé : Mythe. Conte de fées. Orphée. Perrault. Condition. Connaissance de soi.

\section{Introducción}

El tópico de la condición es familiar a los cuentos maravillosos. Habitualmente varios de los personajes deben cumplir con requisitos que ponen en evidencia su naturaleza; concluirlos con satisfacción convierte a uno de ellos en héroe, otorgándole una vida feliz y distinguiéndolo en la comunidad.

La condición desencadena primariamente una indagación y un reconocimiento. Este motivo literario tiene célebre origen; puede rastrearse en el mito del descenso de Orfeo al reino de la muerte en busca de su amada Eurídice y en la condición impuesta por Hades para concederle su deseo; en territorios del inframundo se libra el conflicto entre imposición y cumplimiento de la ley.

Relacionaremos el motivo de la condición a partir de componentes míticos originarios en sede griega, para ubicarlo como eje de la acción en tres cuentos maravillosos que Charles Perrault reescribe a partir de la tradición folklórica europea. Perrault publica en 1697 sus cuentos con el fin de rehabilitar la cultura popular francesa, mostrando su posibilidad de equipararse con la herencia clásica; este objetivo encuadra en la Querelle des Anciens et des Modernes que ocupa su época y en la cual él defiende la causa de los Modernos. Esa postura crítica determinará el uso de sus materiales (Benoit, 2009: 159). No obstante, el núcleo órfico sobrevive a dicha intención, mostrando la autonomía de los motivos míticos.

En línea de análisis mitocrítico, entendemos que el tópico actúa desde el centro de la narración ordenando decisiones esenciales para definir la cuestión antropológica de base; el implícito pedagógico del mito con su saber iniciático estructura el cuento folklórico, aún bajo su forma tardía y simplificada de cuento infantil.

La condición es aplicada en razón de la pervivencia del protagonista, de modo tal que todo el texto se vuelve sobre ese punto central. Seguimos en este enfoque a Pierre Brunel (1992: 61) cuando señala que el mito trabaja siempre como un intertexto que, aunque parezca difuso, hace girar sobre sí el significado global de la narración. Nuestro objetivo es indicar cómo el texto que reformula el motivo mítico converge hacia él como si fuera un imán, permitiendo el despliegue del relato así como el repliegue del sentido.

\section{El mito de Orfeo y Eurídice}

Orfeo se presenta como uno de los personajes más misteriosos de la mitología antigua. Las contradicciones de las fuentes y las reinterpretaciones históricas lo con- 
vierten en una figura proteica. Los relatos sobre sus méritos y desavenencias tienen naturaleza mitificada, es decir, elevada al nivel de tradición ejemplar. Tales narraciones resultaban verosímiles para los griegos antiguos, quienes sí creían en su existencia histórica y lo ubicaban antes de Homero, en la edad de los héroes, y con facultades para el conocimiento de los enigmas del más allá (Guthrie, 1993: 25-27). Su vida está asociada al canto y ello supone la búsqueda de sentido por medios que trascienden lo convencional.

En torno a Orfeo coexisten las visiones de la religión popular y de los primeros pensadores; en una prevalece su don de músico ejemplar, capaz de dominar a la naturaleza inanimada y a las bestias salvajes. En otra, se le aprecia como el fundador de un movimiento religioso. En ambas se reconoce su catábasis, descenso real o simbólico a los infiernos y la ascensión y retorno al mundo de los vivos $o$ anábasis. En el siglo VI a.C. ha alcanzado todo su reconocimiento y comienza a formar parte en las ideas de autores posteriores de enorme influencia para Occidente ${ }^{1}$.

En el relato consignado por Apolodoro, Orfeo simboliza, gracias a su paternidad apolínea, una heroicidad no belicosa que se sirve de la música como vehículo para trascender el límite. No condice con las notas típicas del héroe de las gestas guerreras, carece de fuerza física, no es atlético ni combativo; él es poeta y místico, débil físicamente y superior intelectualmente. Se le atribuyen propiedades chamánicas, capacidad para invocar fuerzas ocultas y hacer curaciones mediante la música (Nagy, 1998: 209). Su atributo es la lira, o bien la cítara, con la cual realiza la hazaña de desafiar a la muerte; su fuerza impulsora es el amor a Eurídice. Por su linaje está en posesión de dotes mágicas, ya que hereda de madre, la musa Calíope, el atributo del canto; desatadas por el dolor de la pérdida, las aplica al rescate de su amada, yendo a buscarla al reino de la muerte. Gracias a la sugestión que su música produce, enfrenta a los guardianes del inframundo y recibe la concesión de recuperar a Eurídice en tanto cumpla una condición.

Así pues por un lado de Calíope y Eagro, por otro según la fama de Apolo, (nacieron) Lino al que mató Heracles, y Orfeo el que tocaba la cítara, que cantando conmovía tanto a piedras como a árboles. Cuando murió su mujer Eurídice, mordida por una serpiente, bajó al Hades queriendo llevarla hacia arriba, y persuadió a Plutón para que la enviara arriba. Este permitió que se hiciera eso, si Orfeo cuando marchara no se volvía antes de llegar a su casa; este que lo ponía en duda, habiéndose vuelto contempló a su mujer, pero ella regresó de nuevo. Orfeo también inventó los misterios de Dioniso, y fue enterrado

\footnotetext{
${ }^{1}$ Para el seguimiento de la influencia de Orfeo, remitimos a los estudios de Guthrie (1993), García Gual y Hernández de la Fuente (2015), Bernabé, Casadesús y Santamaría (2010), Bernabé (2011), Herrero de Jáuregui (2010).
} 
en las cercanías de la Pieria habiendo sido despedazado por las ménades (Apolodoro, 1985: I, 3, 2).

Virgilio, en las Geórgicas, hace hincapié en la proporción entre sufrimiento por la amada y belleza del canto, que consigue hechizar a los habitantes del infierno:

[...] quedaron presos de estupor los reinos mismos de la Muerte en la profundidad del Tártaro, y las Euménides de cabellos trenzados con serpientes azuladas, y el Cérbero se quedó con sus tres bocas abiertas y la rueda de Ixión que voltea el viento se paró (Virgilio, 2009: 481-484).

Ante tal muestra de amor, Hades y Perséfone aceptan devolverle a Eurídice, con la única condición de que no se dé vuelta a mirarla hasta llegar al reino de los vivos; pero Orfeo, en el camino de retorno, temiendo haber sido engañado, se vuelve, la mira y la pierde definitivamente.

La condición muestra una composición básica: "si tú cumples”, entonces, “yo cumplo"; no obstante, tiene una desproporción insalvable: el que impone la prueba está más allá de las categorías en juego, tiene un doble señorío sobre el territorio en el que se da el conflicto; administra vida, muerte y destino, todas las piezas. Aun en el espacio divino del mito, Hades es superior a Orfeo y como autor de las leyes, exige su respeto.

Al incumplirse la exigencia del dios de la muerte, se pierde por completo la posibilidad casi lograda de la restauración de la vida. A partir del fracaso, Orfeo se convierte en un paria, en un solitario que huye desorientado y acabará perseguido y descuartizado. En el mito hay, sin embargo, un atisbo de la derrota de la muerte ya que, aun con sus miembros desperdigados, la cabeza de Orfeo seguirá cantado; hay una vía de trascendencia a través del arte.

\subsection{La condición órfica}

Los componentes del mito se ubican en la frontera humana, territorio que exige un héroe para cruzarla, es decir, para confrontarla. El cruce de territorios, así como el retorno del lugar del que no se vuelve, marca un hito que pervivirá en formatos autónomos en la tradición folklórica. La imagen de la condición cobra estatura fundamental para aludir al límite de las capacidades humanas; en principio, parece afirmar: ni amor ni música, los dos lenguajes más sublimes, pueden contra la muerte individual. El destino de Orfeo, al perder a Eurídice, confirma que la historia se juega en el sinuoso espacio de la fragilidad humana. No obstante el destino trágico, el mito hace una fuerte apelación a la resurrección, al proceso que sigue a la instancia del descenso $y$, aunque se teje a través de un relato que hace hincapié en el no-poder, su permanencia en narraciones folklóricas formula tipos de trascendencia y continuidad positiva.

De la narración básica, tomaremos los elementos constantes para establecer relaciones de presencia en los cuentos maravillosos. El material folklórico que reelabo- 
ran los mitos arrastra componentes religiosos, cuya función ritual ha desaparecido, pero conserva las huellas de cultos de iniciación indispensables para el fortalecimiento del carácter y el pasaje por las etapas clave de la vida².

El relato órfico, en oposición al homérico, no plantea un contraste agudo entre hombre y divinidad (Guthrie, 2012 I: 173). La religión olímpica no da respuesta a la vida después de la muerte y reduce la existencia en el más allá a un deambular sin conciencia. En cambio, en las religiones mistéricas bajo formas de dionisismo, mitraísmo, orfismo, pitagorismo, hay una respuesta a la pregunta por el destino del alma. En la formación del pensamiento occidental, la religión de los misterios, no la homérica, fue la que ejerció influencia vigorosa y esencial. Para el orfismo, salvación es equivalente a liberación del alma de la prisión del cuerpo. No posee la idea de resurrección de la carne que es eminentemente cristiana (Loisy, 1990: 40).

El mito de Orfeo y Eurídice presenta la historia del estado del alma en su proceso de liberación, en el cual debe tomar decisiones de acuerdo con su naturaleza. Allí se presentan las contradicciones: Orfeo es un héroe-artista, cuya fuerza imaginativa tiende a la profecía. Pero depende de quién guíe esa tendencia, lo hará sublime o lo condenará; guiado por Apolo ese vigor se ordena a la concentración, pero si emerge de la fuerza dionisíaca se dispersa en seducciones mundanas (Diel, 1996:132).

En el amor hacia Eurídice se expresa el deseo superior de la aspiración del alma; Eurídice es su estado apolíneo. Por el contrario, las ménades que lo despedazarán al final representan su estado dividido en la multiplicidad de los deseos. En ese punto, Orfeo no puede perder nada más que su carne, pues Eurídice, su alma, ha quedado atrapada en el mundo oscuro. La muerte de Eurídice, picada por la serpiente, significa la caída del alma de Orfeo en las contingencias mundanas: el artista ante el cual hasta los infiernos ceden. Orfeo pierde la unidad de sí, de su alma-Eurídice, ante la fascinación de su propia imagen. Así su alma-luz quedará convertida en sombra, señal de castigo.

Por el contrario, Eurídice representa la pureza del alma que ha caído y debe ser rescatada. El camino de subida representa el sentido verdadero, lo que salva está arriba y adelante; el mirar para atrás simboliza el retorno al falso camino, la desesperación y la destrucción, la pérdida de lo que se ha ganado ascendiendo.

El fracaso en el ascenso indica que siempre hay un accidente que impide la interrelación entre los mundos y expone lo trágico de la existencia (Campbell, 1976: 206); pero aun con fracaso, el regreso lo devuelve distinto, con la conciencia ampliada para sí y para los demás. El impulso hacia Eurídice vale como un combate heroico del que podría haber surgido tanto una victoria como una derrota. La acción de Orfeo cumple el núcleo trágico de enfrentamiento consigo mismo.

\footnotetext{
${ }^{2}$ Así lo postula la perspectiva genetista que vincula mitos y cuentos populares siguiendo sus cambios y continuidades en las sociedades antiguas. Cfr. Eliade (2001) y Van Gennep (2008).
} 
La decisión final del dios queda en entredicho en el concepto órfico; el mismo punto se verifica en el cuento maravilloso.

\subsection{Del mito al cuento}

En el mito de Orfeo se conjugan energías que pueden moverse aisladamente y explican conformaciones cósmicas y psicológicas (eros, thánatos, anánke, logos,) y que, cuando se articulan, generan nuevas dependencias. Tal el caso de dos pares de elementos, cuya duplicidad es aparente, porque la división es más un juego de lenguaje que sustancia de la realidad, si se es fiel a su origen unitario. Por un lado, la unidad música-poesía, por otro, la unidad amor-muerte.

La primera refiere a dos manifestaciones de un mismo lenguaje, a saber, el orden armónico del universo, su descripción, las posibilidades de su tránsito, su incidencia en el gran enigma de la identidad humana y su función en el conocimiento hombre-mundo (Herrero Cecilia, 2001: 18); la segunda refiere a una experiencia capaz de convertir lo transitorio en permanente, representando la plenitud de la existencia, en pugna con su contrario, la ausencia, la pérdida, la nada. El amor como fuerza que irrumpe y desafía, amenazado en simultáneo por la disolución. El antagonismo implícito es materia de la narración, ya para que un polo venza, ya para que esa misma polaridad sostenida sea garantía de equilibrio (Durand, 1993: 36) ${ }^{3}$.

Una situación de pérdida y vulnerabilidad inicia la catábasis al submundo (el sueño como muerte) en cuyo espacio más hondo se da la condición, con carácter de prohibición: ese punto, representado por un dolor insoluble, permite percibir el límite de lo humano y genera la circunstancia propicia para aceptar la condición. De la reacción provocada, positiva o no, se inicia la anábasis. En las reescrituras de los cuentos, se plantea la anábasis o renacimiento como visión ascensional y eventualmente, como posibilidad de trascendencia. El siguiente cuadro ilustra la relación:

\begin{tabular}{|llcll|}
\hline VULNERABILIDAD & CATÁBASIS & CONDICIÓN & \\
& \multicolumn{1}{c}{ RESPUESTA } & ANÁBASIS & HEROICIDAD \\
\hline
\end{tabular}

La trama de los cuentos maravillosos replica el simbolismo de la prueba en contexto profano. Su contenido alude a una relación religiosa, en la cual el hombre es el polo de rebeldía y el dios el polo de enseñanza. Los vestigios del sentido sagrado están presentes en motivos básicos y en presencias aparentemente aleatorias, de seres intermedios, de animales mágicos, de elementos de la naturaleza. Para que el relato tenga una influencia duradera, debe enfrentar al hombre con las causas últimas del universo.

\section{La condición en los cuentos de Charles Perrault}

Charles Perrault publica en 1697, Histoires et contes du temps passé avec des

${ }^{3}$ El antagonismo funciona como premisa para desarrollar el sentido según Durand (1993: 90). 
moralités, ou Contes de ma Mère l'Oye, obra que contiene narraciones centrales para la literatura infantil: Peau d'âne, La Belle au Bois dormant, Le petit chaperon rouge, Barbe-Bleue, Le Maître Chat ou Le Chat botté, Les Fées, Cendrillon ou La Petite Pantoufle de Verre, Riquet à la Houppe, Le petit Poucet. Autor de minuciosa cultura, su formación excedía el curriculum convencional de la época (Knapp, 2003: 65). Tomamos tres ejemplos de los cuentos en los cuales está presente la condición órfica.

En el dúo de protagonista y antagonista, uno divino, el dios de los muertos, el otro humano, en estado de incertidumbre, se denota un conflicto que parece resolverse con el cumplimiento de una prueba. Uno es el dueño del lugar y por tanto escribe las leyes, el otro está en estado de dependencia; aquél es inflexible y éste debe obedecer. En la elaboración de los argumentos, Perrault se dirige a una audiencia formada, adulta, y mayoritariamente femenina, impactando con tópicos alejados de lo tradicional, como veremos en el segundo y en el tercer ejemplo (Hennard Dutheil de la Rochère y Heidmann, 2009: 43).

En La Belle au Bois dormant, los reyes, felices por haber concebido al fin una hija, celebran su bautismo con toda pompa. Invitan a las hadas de la comarca, siete en total, para que cada una otorgue un don a la niña y así dotarla con todos los atribu$\operatorname{tos}^{4}$. En el banquete posterior al bautismo, cada una de las hadas ocupa su lugar, frente a cubiertos de oro con incrustaciones de diamantes y rubíes. Pero en ese momento, se presenta un hada vieja, a la cual no habían invitado por creerla muerta o encantada, pues hacía cincuenta años que no salía de su encierro. El rey manda colocar cubiertos para la recién llegada, pero ya no quedaban de oro, pues solo había mandado fabricar siete. El hada se ofende y amenaza por lo bajo5. Una de las hadas buenas, la más joven, escucha la amenaza y, sabiendo el riesgo que supone, se esconde detrás de un cortinado de la sala para pasar desapercibida y reservarse el último lugar en la entrega de los regalos a la princesa. Llegada la hora, las seis hadas buenas otorgan sus dones, de hermosura, bondad, gracia, habilidades. Al llegar su turno, el hada vieja lanza su deseo de que, cuando alcance la doncellez, la niña se pinche con un huso y muera al instante 6 . Nadie puede hacer nada, más que asustarte y llorar; los padres caen en un estado de tristeza total. Hasta que el hada más joven sale de su escondite y, si bien es incapaz de destruir el hechizo, conjura la maldición: es inevitable que la

\footnotetext{
4 “[...] on fit un beau baptême; on donna pour marraines à la petite princesse toutes les fées qu'on pût trouver dans le pays (il s'en trouva sept), afin que chacune d'elles lui faisant un don, comme c'était la coutume des fées en ce temps-là, la princesse eût par ce moyen toutes les perfections imaginables" (Perrault, 1968: 30).

5 "Le roi lui fit donner un couvert; mais il n'y eut pas moyen de lui donner un étui d'or massif comme aux autres, parce que l'on n'en avait fait faire que sept pour les sept fées. La vieille crut qu'on la méprisait, et grommela quelques menaces entre ses dents" (Perrault, 1968: 31).

6 "Le rang de la vieille fée étant venu, elle dit, en branlant la tête encore plus de dépit que de vieillesse, que la princesse se percerait la main d'un fuseau, et qu'elle en mourrait” (Perrault, 1968: 32).
} 
princesa se pinche con el huso, pero en lugar de morir, dormirá durante cien años, después de los cuales llegará a despertarla el hijo de un rey ${ }^{7}$.

Hasta aquí los componentes de la trama que nos ocupan, pues el cuento de Perrault es más extenso, con dos partes bien diferenciadas argumentalmente; en el momento del bautismo de la princesa, el hada ofendida por no haber sido reconocida en su dignidad, lanza una maldición extrema, que será moderada por una última bendición del hada faltante. El motivo es un error insignificante y, sobre todo, no intencional de los padres de la niña. Pero, una vez acontecido, no permite retorno. El hada vieja "expresó su deseo de que cuando la niña llegase a doncella, se pinchase el dedo con un huso y muriese de la herida" (Perrault, 2000: 60). El rey emite de inmediato una orden contra todos los husos del reino como inútil resistencia al destino, pues, cuando ella alcance los quince años, todo se cumplirá según ha quedado predicho.

El hada es la dueña del destino de la princesa, como indica su conexión etimológica (Harf-Lancner, 1984: 9); la Parca hila, extiende y corta. Su función es negar la doncellez por medio de la condena a muerte. El paliativo lo ofrece un hada buena, testigo de la injusticia del castigo, y será trastocar la muerte en sueño para permitir que el amor de un príncipe (nuevo Orfeo) la salve. La princesa, como Eurídice, queda suspendida en el reino del sueño, hermano de la muerte. El príncipe entra en él, cumplidos los cien años de la segunda condición, y la recibe una vez concluido el tránsito por el espacio de la muerte. El sueño es transición y confiere beneficio a la víctima. Los cien años, el castillo detenido y el bosque de zarzas permiten dar los pasos ascendentes hacia la luz.

En La Belle au Bois dormant la condición no es violada por su destinatario, sino aminorada por un agente del destino, menor pero eficiente, para asignar buena fortuna. Aparece como elemento propicio para la dicha final y, en mirada retrospectiva, hace pensar que, sin error de protocolo hacia el hada vieja, no habría retribución. $\mathrm{Su}$ figura recrea el agente del mal presente en todas las religiones, Eris que irrumpe para disputar la felicidad humana. La alianza entre condición del dios de la muerte y configuración final de las Parcas es positiva, ajustada a términos de justicia inmanente: no hay culpa en la princesa, es emisaria de virtudes, su vida es fuente de alegría para los demás, por ende, merece vivir.

En este cuento, la condición queda atemperada y resignificada.

En el segundo ejemplo elegido, Barbe-Bleue, aparece la figura del protagonista como dios del inframundo, poderoso, rico, de aspecto horrible; aunque se ha casado

7 “[...] il est vrai que je n'ai pas assez de puissance pour défaire entièrement ce que mon ancienne a fait. La princesse se percera la main d'un fuseau; mais au lieu d'en mourir, elle tombera seulement dans un profond sommeil qui durera cent ans, au bout desquels le fils d'un roi viendra la réveiller" (Perrault, 1968: 32). 
antes y varias veces, todas sus mujeres han desaparecido ${ }^{8}$. Barba Azul, como Hades, reclama una esposa.

A pesar de las sospechas, la seducción de su caballerosidad y de sus riquezas le permite ganar a la más joven de las hijas de su vecina, una dama de alto linaje, con la cual contrae matrimonio. Enseguida se presenta la oportunidad para el conflicto: ante un viaje de negocios que lo mantendrá lejos de la casa, el esposo entrega a la esposa las llaves de todos los cuartos donde guarda sus variadas riquezas, dándole acceso a ellas; solo le advierte con insistencia por la llave de un gabinete prohibido. Explícitamente le concede abrir todas las puertas, menos esa, bajo pena de suscitar su enojo?

La condición es impuesta por un esposo, dios de la muerte, que legisla sobre la vida como sobre el resto de sus posesiones: “[...] ouvrez tout, allez partout, mais pour ce petit cabinet, je vous défends d'y entrer, et je vous le défends de telle sorte, que s'il vous arrive de l'ouvrir, il n'y a rien que vous ne deviez attendre de ma colère" (Perrault, 1968: 57). A pesar de la claridad de la advertencia, es tan fuerte la tentación de la esposa que desobedece, es descubierta y de inmediato condenada a morir. En lo hondo del infierno, buscará la salvación, que no puede venir de la piedad del esposo, sino del rescate de emisarios del mundo exterior. La esposa sabe que sus hermanos están por llegar y solo necesita retrasar el castigo, por lo cual pide tiempo para rezar las últimas oraciones; la artimaña se convierte en salvación ${ }^{10}$. Los hermanos prestos funcionan como un Orfeo que entra en territorio de la muerte para arrancarla; tan bien cumplen su misión que no solo vencen al cruel esposo, sino que al convertirla en heredera de su enorme fortuna, le permiten ayudar a su hermana a encontrar esposo y a ellos mismos favorecerlos en la carrera militar. La joven mujer vuelve a casarse con un hombre bueno que le permite olvidar los horrores vividos.

En este ejemplo, el paso por la condición quebrada resulta en beneficio final, en concreto renacimiento. Barba Azul-Hades entrega la llave que lleva a la caída, pero la culpa es menor. La curiositas, como identificación de la femineidad en la tradición literaria, es delito menor ante el deseo de Hades de tragar a sus víctimas. La descalifi-

8 "Il était une fois un homme qui avait de belles maisons à la ville et à la campagne, de la vaisselle d'or et d'argent, des meubles en broderie et des carrosses tout dorés; mais par malheur cet homme avait la barbe bleue: cela le rendait si laid et si terrible, qu'il n'était ni femme ni fille qui ne s'enfuît de devant lui" (Perrault, 1968: 55).

9 "Pour cette petite clef-ci, c'est la clef du cabinet au bout de la grande galerie de l'appartement bas: ouvrez tout, allez partout, mais pour ce petit cabinet, je vous défends d'y entrer, et je vous le défends de telle sorte, que s'il vous arrive de l'ouvrir, il n'y a rien que vous ne deviez attendre de ma colère" (Perrault, 1968: 57).

10 "- Cela ne sert de rien, dit Barbe-Bleue, il faut mourir.

Puis la prenant d'une main par les cheveux, et de l'autre levant le coutelas en l'air, il allait lui abattre la tête. La pauvre femme se tournant vers lui, et le regardant avec des yeux mourants, le pria de lui donner un petit moment pour se recueillir. - Non, non, dit-il, recommande-toi bien à Dieu; et levant son bras [...]" (Perrault, 1968: 64). 
cación moral de Barba Azul lo inhabilita para poner condición, en tanto esta debe ser salvadora. El principio vital se sobrepone y reinicia el ciclo sostenido en el nuevo marido, calificado simplemente como "hombre honesto"11.

No obstante, esta variante de la desobediencia requiere una precisión: cuando la esposa abre el gabinete secreto, se encuentra con los cadáveres de las mujeres anteriores y naturalmente, el terror la domina, porque ve su propia muerte. La condición del esposo impedía que la joven conociera su destino. Nada indicaría entonces, según la lógica de los sucesos, que la nueva esposa tuviera mejor fortuna. Su violación consiste en que se atrevió a verlo y eso no puede ser perdonado. El acceso a los secretos del otro mundo es punido con la muerte.

En este cuento, la condición queda invalidada y debe ser desobedecida.

En el tercer ejemplo, Peau d'âne, hay una sucesión de condiciones encadenadas, pero en grado subalterno a la propiamente órfica: el Padre-Hades al elegir a su hija como objeto de amor, la condena a muerte (en el incesto radica a la vez el deshonor de la hija como el egoísmo del padre); esta condición, que es la principal y contra la que resiste la protagonista, depende del pedido de la esposa al rey en el lecho de muerte. La moribunda, conociendo el temperamento pasional del marido, le exige un juramento: solo casarse si encuentra a una mujer más bella y discreta que ella mis$\mathrm{ma}^{12}$. El pedido es artero, pues la reina es consciente de su belleza superior, y más que conceder permiso, está dando una prohibición.

Bajo esas circunstancias, la condición ciñe al esposo y terminará alimentando su deseo incestuoso: “[...] mais je vous demande instamment, par tout l'amour que vous avez eu pour moi, de ne céder à l'empressement de vos peuples que lorsque vous aurez trouvé une princesse plus belle et mieux faite que moi” (Perrault, 1968: 6).

En cumplimiento del pedido, el rey requiere a su hija en matrimonio ${ }^{13}$. En tal situación, entra en escena el hada madrina, como moderadora del destino, en función de parca auxiliar que equilibra las cargas repartidas. La madrina es un hada ilustre, sin rival en su arte, que sabe que no es posible ir contra la designación, pero que sí se puede tomar un atajo ${ }^{14}$.

Una vez más funciona el recurso de dilatar el tiempo para retardar el cumplimiento. Propone, a modo de prueba del amor, tres deseos en apariencia igual de inal-

\footnotetext{
11 "[...] et le reste à se marier elle-même à un fort honnête homme, qui lui fit oublier le mauvais temps qu'elle avait passé avec la Barbe-Bleue” (Perrault, 1968: 67).

12 “[...] mais je vous demande instamment, par tout l'amour que vous avez eu pour moi, de ne céder à l'empressement de vos peuples que lorsque vous aurez trouvé une princesse plus belle et mieux faite que moi ; j'en veux votre serment et alors je mourrai contente" (Perrault, 1968: 6).

${ }^{13}$ Es visible la analogía con Perséfone y su unión con su madre Démeter, en particular por la confusión entre la identidad de ambas para el padre-esposo.

14 "- Car, ma chère enfant, lui dit-elle, ce serait une grande faute que d'épouser votre père; mais, sans le contredire, vous pouvez l'éviter" (Perrault, 1968: 10).
} 
canzables: vestidos color tiempo, color luna y color sol, obstáculos que sin embargo, el rey resuelve. Una cuarta alternativa, imposible según estima el hada, es pedirle que entregue la fuente de su riqueza, a saber, la piel de un asno extraordinario, que echa escudos de oro en lugar de excremento. Contra todo pronóstico, el rey resuelve todos los impedimentos con tal de casarse con la princesa.

En ese punto límite, en que la tensión de los deseos de uno y otro lado resultan balanceados, se plantearía la entrada al Hades de la protagonista, simbolizada como en Barbe-Bleue, por la boda. Pero se produce la huida, inicio de liberación y ascenso: con la misma piel de asno que le entrega el padre, disimula otra identidad e inicia un camino de soledad, pobreza y desprecio al final del cual la espera un príncipe enamorado. Así como con los vestidos buscaba cambiar su identidad para resolver su problema (Knapp, 2003: 72), la piel de asno constituye el medio para el engaño que le permite escapar del reino infernal, al tiempo que es el símbolo de su simulación necesaria para defender la auténtica naturaleza. Hay una red de condiciones y hay una superposición de identidades, hija que quiere ser convertida en esposa, joven bella que se $\mathrm{afea}^{15}$. Bajo esa piel empieza su peregrinaje interno hasta que un buen príncipe la rescata, la ve a pesar del encubrimiento y se casa con ella. En este cuento, la condición inicial es ambigua (pedido de esposa en el lecho de muerte), genera una extrema (la pretensión del padre sobre la hija) que a su vez se dilata en mínimas condiciones formales para diferir la acción. La red establecida retarda el doble proceso de descenso-ascenso. Más allá de la pruebas, el itinerario de la princesa inicia con las vicisitudes del mundo exterior al palacio y le permite recuperar el tratamiento de su dignidad.

\section{Relación del motivo mítico en los tres cuentos}

El paso por la condición se hace indispensable para el cumplimiento del relato, el cual es una metáfora del destino. En los textos señalados se observa cómo el motivo de la condición órfica opera como articulador de la trama y medio de desenvolvimiento de la historia del protagonista, que al asumirlo, se expande. En términos de José Manuel Losada (2016: 70), se encuentran "los elementos invariantes reducibles a temas y sometidos a crisis"; cada reescritura propone el tipo de crisis en adecuación general al interés y al contexto del autor.

Perrault funciona como conjunción original entre apropiación de los modelos folklóricos, intención política de su obra y aportación personal. La profunda influencia que tendrá en la historia del cuento maravilloso se denota en que no es posible determinar qué cuentos son reescrituras y qué originales; y no hay duda acerca de la repercusión que tuvo la publicación de su obra en la literatura (Jean, 2007: 282).

15 "L'infante embrassa mille fois sa marraine, la pria de ne pas l'abandonner, s'affubla de cette vilaine peau, après s'être barbouillée de suie de cheminée, et sortit de ce riche palais sans être reconnue de personne" (Perrault, 1968: 14). 
Los elementos del conjunto órfico, música, muerte, amor se conjugan. El siguiente cuadro establece las correlaciones:

\begin{tabular}{|l|c|c|c|}
\cline { 2 - 4 } \multicolumn{1}{c|}{} & La Belle au Bois dormant & Barbe-Bleue & Peau d'àne \\
\hline MÚSICA & Hada buena-sueño & Pedido de oración-hermanos & $\begin{array}{c}\text { Hada madrina-Piel de } \\
\text { asno }\end{array}$ \\
\hline MUERTE & Doncellez truncada & Casamiento & Amenaza de boda \\
\hline AMOR & Victoria final & Victoria final & Victoria final \\
\hline
\end{tabular}

La muerte-Hades es la voz del destino corporizada como autoridad que hace cumplir leyes. Fácilmente se conecta la imagen de Platón ${ }^{16}$, cuando describe a la Necesidad (Anánke) como una diosa que sostiene el huso sobre el que giran las estrellas, con la viejecilla que espera hilando a la princesa en lo alto del castillo.

En el cuento, la muerte opera como desaparición o disminución de la vida, pero en ningún caso se presenta absoluta, sino como estado de transición. La muerte es presencia arbitraria de un estado que debe superarse; está impuesta por un poder supremo, pero no invulnerable. La muerte y la noche operan en símil. La oscuridad es propia del inframundo y necesaria para recibir la revelación. El proceso de conocimiento tiene en su punto de descenso, una purga necesaria para la revelación que obtendrá al ascender.

El amor está en el punto de llegada, de modo que se invierte el modelo órfico; no es hilo conductor, causante de la desobediencia a la condición, sino que espera como signo de victoria. Responde al modelo órfico, en cambio la idea de purificación mediante el sufrimiento ofrecida por el amante al amado: se salva el que es amado por el amor del otro. Las jóvenes mujeres protagonistas son pasivas ante el amor, como en La Belle au Bois dormant, o escapan de él porque las obligan a su deformación, como la esposa en Barbe-Bleue o la princesa en Peau d'âne. El amor es móvil cósmico de restauración y ellas representan el orden quebrado del cosmos; por eso deben ser amadas y curadas, antes que amar por ellas mismas.

El componente persuasivo para entrar o salir del mundo inferior, equivalente a la música órfica, se convierte en recurso justo contra una imposición arbitraria. Como supone el encantamiento por facultades más que humanas, así como a Orfeo lo asisten los poderes del canto de Apolo, a las protagonistas del cuento las asisten las hadas, capaces de frenar el fluir del destino. No es excepción el recurso de la esposa de

${ }^{16}$ El mito de Er, el armenio, combina la tradición órfico-pitagórica. El soldado presencia el juicio de las almas y se le permite volver a la vida para comunicar lo visto a los vivos. Cfr. Droz (1992: 110, n.5) : “[...] el huso de la Necesidad, a través del cual giraban las esferas (...) En cuanto al huso mismo, giraba sobre las rodillas de la Necesidad (...) y había tres mujeres sentadas en círculo a intervalos iguales, cada una en su trono; eran las Parcas, hijas de la Necesidad, vestidas de blanco y con guirnaldas en la cabeza, a saber, Láquesis, Cloto y Átropo, y cantaban en armonía con las sirenas: Láquesis las cosas pasadas, Cloto las presentes y Átropo las futuras. Las tres hacían girar el huso y repartían a los hombres que llegaban los lotes de vida que ellos debían escoger” (Rep. 616 c-617 b). 
Barba Azul, quien pide tiempo para rezar y prepararse a morir, pues el puente hacia lo sobrenatural -la fuerza benéfica de las oraciones- es el freno para el cumplimiento de la condena indebida. La piel de asno oficia de música encantadora; así como el animal, sublimaba su digestión en oro, mineral de los dioses, y era el último reaseguro espiritual del rey librado a sus pasiones, su piel, entregada a la hija, será el instrumento divino de protección que le permite renovar su destino.

La transmisión del mito órfico se hace presente en la administración de la vida que pone el dios Hades o el hada Parca y en el atajo que toma la vida para imponerse a través de agentes menores de la voluntad. Tiene que ver con un recurso de la inteligencia jugado como artimaña, que así como en el mito es llevado como un duelo entre poderes divinos (encantamiento/castigo) en el cuento es traducido en intervenciones mágicas: sueño en lugar de muerte, tiempo para esperar la llegada de los hermanos, piel de asno como vestimenta. En el modelo mítico hay enfrentamiento de jerarquías que parecen infranqueables, pero quien dirime la batalla es finalmente la voluntad: Hades impone, Hades castiga el incumplimiento, pero Orfeo seguirá cantando para atraer a Eurídice aun cuando solo le quede su cabeza.

Es semejante la asimilación en el cuento maravilloso: los símiles de Hades se imponen con más autoridad, pero las voluntades de los seres menores son las que triunfan; al tratarse de Perrault, además, se añade la importancia del componente moral que hace superiores a los débiles. Su competencia con las fábulas clásicas lo lleva, sin ser un folklorista, a elaborar materiales moralmente edificantes que equiparan la función formativa acaparada por aquellas (Vaz da Silva, 2016: 168). La vulnerabilidad, que había sido ocasión para que una fuerza maligna se impusiera, revierte en fortaleza. Los cuentos confirman el valor de la elección buena, no condicionada; a través de ella es posible la revelación de sí y, por ende, vale de vía de autoconocimiento. En el cuento maravilloso la desobediencia no es leída en término de rebeldía, sino que se ofrece una revalorización de la ruptura del protagonista en tanto que la prueba heroica, ya sea que alcance la muerte o la victoria, igualmente es causa de trascendencia.

Al corregir el destino prefijado, se desvela la apariencia de una vida falsa. Así como en los misterios iniciáticos se instruía para la vida después de la muerte, haciendo hincapié en la carga de recompensas y castigos (Guthrie, 2012 I: 480), también en el cuento permanecen las nociones de premio y sanción como vías purificatorias.

Podemos reubicar las representaciones de los seres mitológicos en el entramado de estos cuentos maravillosos: 


\begin{tabular}{|l|l|l|l|}
\cline { 2 - 5 } \multicolumn{1}{c|}{} & \multicolumn{1}{c|}{ La Belle au Bois dormant } & \multicolumn{1}{c|}{ Barbe-Bleue } & \multicolumn{1}{c|}{ Peau d'âne } \\
\hline Orfeo & $\begin{array}{l}\text { Amado en estado de la- } \\
\text { tencia que moviliza el } \\
\text { desenlace }\end{array}$ & $\begin{array}{l}\text { Hermanos protectores } \\
\text { de la justicia familiar. } \\
\text { Esposo honesto }\end{array}$ & $\begin{array}{l}\text { Amado en estado de } \\
\text { latencia que moviliza el } \\
\text { desenlace }\end{array}$ \\
\hline Eurídice & $\begin{array}{l}\text { Princesa dormida, en } \\
\text { estado de muerte. Inocen- } \\
\text { te de culpa, pero curiosa. }\end{array}$ & $\begin{array}{l}\text { Esposa apresada en su } \\
\text { matrimonio. Inocente } \\
\text { de culpa, pero curiosa. }\end{array}$ & $\begin{array}{l}\text { Princesa pasiva, víctima } \\
\text { de su belleza. Resistente y } \\
\text { astuta. }\end{array}$ \\
\hline Hades & $\begin{array}{l}\text { Hada vieja. Fuerza supra- } \\
\text { racional que defiende un } \\
\text { orden jerárquico. }\end{array}$ & $\begin{array}{l}\text { Fuerza unitaria, inexo- } \\
\text { rable, legisladora del } \\
\text { orden de su universo. }\end{array}$ & $\begin{array}{l}\text { Fuerza personal pero } \\
\text { condicionada doblemen- } \\
\text { te, por juramento y por } \\
\text { carácter. }\end{array}$ \\
\hline
\end{tabular}

Los tres ejemplos muestran el tránsito anábasis-catábasis y postulan el ascenso final, ejemplificado como triunfo del amor nuevo sobre la muerte programada. El mito órfico provee material sobre el retorno a la vida con intención de acercar una revelación, con carácter de advertencia, de parte de los dioses; el fin es procurar una vida virtuosa, particularmente justa, y evitar sanciones en el más allá. En el mito funciona la premisa de que las almas están sometidas a reencarnación y después de morir y descender al mundo inferior, retornan a la vida. En el cuento cambia esta visión escatológica haciéndose inmanente. El cambio de vida o paso de la muerte a la vida implica una conversión del destino, una mejora en la situación, retribución pendiente o aplicación de una justicia proporcional a la naturaleza del personaje.

La interacción de personajes hijos de dioses y mortales alude a la doble naturaleza espiritual y mortal del hombre. Los primeros son interlocutores sagrados que hacen puente por el bien del destino humano. Desde que el hombre se separa de la divinidad, está pendiente de su purificación para recuperar su lugar de origen.

La mujer, niña, joven, princesa, esposa, opera como principio generador femenino; como sujeto de dedicación, es la imagen en torno a la cual permanece el héroe. Es la figura que despeja las tinieblas de la noche y prepara el amanecer. En ella convergen los deseos de superación que definen la heroicidad; por ende, lo femenino es ámbito de constancia y estabilidad. La mujer comparte algo de la posesión del destino con las hadas, ya porque la asisten, ya porque le dan valentía para actuar; tanto en el politeísmo como en el monoteísmo, los poderes animizados femeninos remiten a las fuerzas maternales que pueden invocarse en busca de ayuda (Knapp, 2003: 70).

\subsection{La prohibición de la vista}

La condición órfica se centra en prohibir la visión de lo deseado. El dios de la muerte hace desaparecer los seres y las cosas de la superficie de la tierra.

Los cuentos sostienen igualmente la exigencia de la no-visión: en La Belle au Bois dormant, a través de la suspensión de la vida por el sueño de la princesa junto con todos los habitantes y por el aislamiento completo del reino; en Barbe-Bleue, a través de la estricta orden del esposo de no abrir (no-ver) uno entre todos los gabine- 
tes permitidos; en Peau d'âne, la huida del hogar y el disimulo de la identidad (la novisión de la princesa) neutraliza la intención de las extrañas condiciones previas. En cada caso, se verifica la afirmación de Carlos García Gual (2015: 18) en su texto sobre el mito de Orfeo acerca de que "[la mirada] es el tabú impuesto por la divinidad de los muertos”. Como ley cósmica, confirma la necesidad de mantener secreto y cerrado el dominio del misterio.

Pero, esto contradice la tendencia del hombre a indagar, descubrir, conocer, la innata curiosidad por la que conquista y amplía sus límites; esa predisposición va contra el mandato. En sentido platónico "la visión es el acto espiritual por excelencia" (Droz, 1992: 80). Por lo tanto, los movimientos, que en una interpretación precipitada pueden parecer desobediencia, se explican mejor como reacciones propias del desafío original del hombre ante los límites impuestos por los dioses, que son los límites de su propia naturaleza; esa ruptura está en la raíz del mal y del estado de caída (Ricœur, 1988: 384).

Tanto en tradición órfico-platónica como cristiana, la prueba tiende a ser una descripción de lo humanamente posible en orden a preservar el estado de equilibrio original, aunque su representación se haga luego de la caída, en el devenir de la historia. Si ya hay caída, también hay dolor y deseo de retorno a un estado virginal del universo. Dado que no es posible y, en tanto la noción de caída implica indefectiblemente culpa (de distinto tipo, individual o generacional, subjetiva u objetiva), requiere de un doble proceso, el de purificación y el de redención. La culpa no es condenatoria en ninguno de esos contextos, antes bien, es posibilidad de ascenso y liberación. Pero debe darse un acto de inmersión libre, consciente, momento en el que actúa la decisión. Las imágenes de la purificación se diversifican en pruebas duras y humillantes y en astucias de la inteligencia para sobreponerse, así como las figuras intermedias aligeran la inflexibilidad del destino y se dedican a proteger torciendo las disposiciones de divinidades hostiles; no representan la libertad del héroe, pero preparan circunstancias favorables para que se produzca el ascenso.

El mito órfico ubica el acto de la visión como meta necesaria del autoconocimiento, antes que como derecho negado, pues implica la comprensión intelectual de la propia existencia. Por eso, la prohibición procede de fuerzas cósmicas contrariadas y la facilitación la permiten fuerzas cósmicas allegadas al hombre, una dicotomía de antiguos dioses de reminiscencia homérica que acentúan la distancia con los hombres, y nuevos dioses, que buscan su bien. La tradición del cuento maravilloso asume la segunda por su impronta de platonismo con componentes cristianos. En ambos, el hombre juega un papel activo en la elaboración de su fortuna.

\section{Conclusiones}

Es posible establecer la analogía entre el contexto del mito órfico y el ámbito pre-lógico en el que se enmarcan los cuentos maravillosos. Si bien en cada cuento 
pueden converger varios motivos míticos, hemos seguido uno predominante que muestra su fuerza centrípeta sobre trama y resolución.

La condición órfica opera de trasfondo que confirma la presencia de lo sagrado en las circunstancias humanas: en tanto ligazón religiosa, tiene implicaciones éticas, pues lo divino reclama un acto de vinculación; la acción que responde a la interpelación de lo divino refleja un modo de ser. Como el protagonista es un ser en tránsito, es decir, en proceso de crecimiento y formación, puede haber dudas, errores e imperfecciones; recordemos el símil con ritos iniciáticos y el valor preparatorio de las experiencias para la vida adulta. La prueba entonces deviene en ejercicio pedagógico.

En la relación de elementos, observamos un claro conflicto entre imposición y cumplimiento de la ley; la noción de orden está representada de modo absoluto por el Destino personificado en diversas figuras, pero con igual nota de imperturbabilidad, propia de la cosmovisión griega arcaica. Frente a él, la posición del protagonista que ensaya un nuevo tipo antropológico.

Esta noción ya está planteada en el mito originario cuando Orfeo, aparentemente derrotado dos veces por la muerte (pérdida de su alma-Eurídice y descuartizamiento) sigue cantando con su cabeza separada del cuerpo. Si la condición implica límite y el personaje lo rechaza, se abre una tangente que pretende superar la predeterminación. En los cuentos se denota lo arbitrario de quien impone la condición, en todos los casos figuras desquiciadas: un hada ofendida, un esposo asesino, un padre incestuoso. Esa polarización favorece la desobediencia y concentra la decisión sobre el destino en el propio sujeto. La condición, entonces, se vuelve autocondición, espejo de las posibilidades propias, no de un dios maligno exterior. Las huellas de los ritos de iniciación acentúan que la formación tiene una exigencia firme de autoformación y que el proceso supone la aventura de hacerse humano, metaforizado con el premio de felicidad al final del camino.

Eurídice llama a Orfeo, siempre. Pero Orfeo solo es tal cuando la ha perdido. El mito expone un arquetipo en que el sentimiento de nostos define y justifica los esfuerzos. En los cuentos, suavizado el rigor de la dualidad rota, las figuras que asumen a Eurídice sirven de impulso ascensional, sosteniendo el ideal. El imperativo cíclico, que queda inmerso en el contexto cristiano de los cuentos, sirve para abrirlos a un final siempre augural: los cuentos maravillosos terminan con la iniciación de un nuevo ciclo.

La música de Orfeo suena en los recursos de disuasión que impiden la derrota y postulan la confianza en una alternativa maravillosa o natural, un hada madrina, un ruego, un engaño. Cada uno tiene un arma provista por los dioses, un logos para defenderse con variedad de formas. El mito ha servido en este tránsito para objetivar una vez más una experiencia individual que se repite en las edades del mundo. 


\section{REFERENCIAS BIBLIOGRÁFICAS}

ApOlodoro (1985): Biblioteca, Int. Javier Arce. Trad. y notas Margarita Rodríguez de Sepúlveda. Madrid, Gredos.

ApOllodori (2013): Bibliotheca. Pediasimi libellus de duodecim Herculis laboribus, Ed. Richard Wagner. Berlín, W. De Gruyter (Bibliotheca scriptorum Graecorum et Romanorum Teubneriana).

BENOIT, Jean-Louis (2009): "Qui est le loup dans Le Petit Chaperon rouge de Charles Perrault ?». BULETINUL, LXI (1), 159-163.

BernabÉ, Alberto, Francesc CASADEsús y Marco Antonio SANTAMARÍA [eds.] (2010): Orfeo y el orfismo: nuevas perspectivas. Biblioteca Virtual Cervantes. Disponible en: http://www.cervantesvirtual.com/obra/orfeo-y-el-orfismo-nuevas-perspectivas-0.

BERNABÉ, Alberto (2011): Platón y el orfismo. Diálogos entre religión y filosofía. Madrid, Abda Editores.

BRUnEL, Pierre (1992): Mythocritique. Théorie et parcous. París, Presses Universitaires de France.

CAMPBELl, Joseph (1976): The Masks of God: Occidental Mythology. Nueva York, Penguin Books.

DIEL, Paul (1996): El simbolismo en la mitología griega. Barcelona, Labor.

DROZ, Geneviève (1992): Los mitos platónicos. Barcelona, Labor.

DURAND, Gilbert (1993): De la mitocrítica al mitoanálisis. Traducción de Alain Verjat. Barcelona, Anthropos.

ELIADE, Mircea (2001): Nacimiento y renacimiento: el significado de la iniciación en la cultura humana. Barcelona, Kairós.

García GuAl, Carlos y David HernándeZ de la Fuente (2015): El mito de Orfeo. Estudio y tradición poética. Madrid, Fondo de Cultura Económica.

GuTHRIE, William Keith (1993): Orpheus and Greek Religion: A Study of the Orphic Movement. Princeton (Nueva Jersey), Princeton U. P.

GUTHRIE, William Keith (2012): Historia de la filosofía griega I. Los inicios y los presocráticos. Prólogo de C. García Gual. Madrid, Gredos.

HARF-LANCNER, Laurence (1984): Les Fées au Moyen Âge. Ginebra, Slatkine.

HenNaRd Dutheil de LA Rochère, Martine and Ute HeIdmanN (2009): "New Wine in Old Bottles": Angela Carter's Translation of Charles Perrault's "La Barbe bleue". Marvels \& Tales: Journal of Fairy-Tale Studies, 23 (1), 40-58.

Herrero CeCiliA, Juan (2011): "Figuras y significaciones del mito del doble en la literatura: teorías explicativas". Çédille, revista de estudios franceses, Monografías 2 (Juan Herrero Cecilia, ed.: El mito del doble en la literatura contemporánea de lengua francesa: $f_{i-}$ guras y significados), 15-48. Disponible en: http://cedille.webs.ull.es/index-M2.htm.

Herrero de JÁUREgUI, Miguel (2010): Orphism and Christianity in late Antiquity. Berlín y Nueva York, Walter de Gruyter. 
JEAN, Lydie (2007): "Charles Perrault's Paradox: How aristocratic Fairy Tales became Synonymous with folklore Conservation”. TRAMES, 11(61/56), 3, 276-283.

KNAPP, Bettina (2003): French Fairy Tales. A Jungian Approach. Nueva York, State University of New York.

LOSADA, José Manuel (2016): "El mundo de la fantasía y el mundo del mito. Los cuentos de hadas". Çédille, revista de estudios franceses, Monografías 6 (Esther Bautista Naranjo, ed., Literatura fantástica hispano-francófona actual), 69-100. Disponible en: http://cedille.webs.ull.es/M6/04losada.pdf.

LOISY, Alfred (1990): Los misterios paganos y el cristianismo. Traducción de Ana P. de Godar. Barcelona, Paidós.

MiTTS-SMiTH, Debra (2007): "The Wolf: Danger and Deception in Three Tales". The Princeton University Library Chronicle, 68 (3), 941-959. Disponible en: https://www.jstor.org/stable/10.25290/prinunivlibrchro.68.3.0941

NAGY, Joseph F. (1989): "Hierarchy, Heroes and Heads: Indo-European Structures in Greek Myth", in Lowell Edmunds, ed., Approaches to Greek Myth, Baltimore (Maryland), Johns Hopkins U.P.

Perrault, Charles (1697 [1930]): Contes de Perrault. París, Librairies-Imprimeries Réunies L. Martinet (col. Bibliothèque de la Jeunesse et de l'Enfance). Disponible en: https://data.bnf.fr/fr/12073543/charles_perrault_contes.

Perrault, Charles (1968): Contes de ma mère l'Oye. Québec, La Bibliothèque électronique du Québec (col. À tous les vents. Volume 61: version 1.02 Éditions Rencontre). Disponible en: https://beq.ebooksgratuits.com/vents/Perrault-contes.pdf.

Platón (1988): Diálogos IV, República. Intr. trad. y notas de Conrado Eggers Lan. Madrid, Gredos.

RICEUR, Paul (1988): Philosophie de la volonté II. Finitude et culpabilité. París, Aubier Flammarion.

VAN GENNEP, Arnodl (2008): Los ritos del paso. Madrid, Alianza.

VAZ DA SILVA, Francisco (2016): "Charles Perrault and the Evolution of Little Red Riding Hood”. Marvels \& Tales: Journal of Fairy-Tale Studies, 30 (2), 167-190.

VirgiLIO MARONE (2009): Georgiche. Testo latino a fronte, trad. M. Ramous. Milán, Garzanti Libri.

Para citar este artículo / Pour citer cet article :

JUNCO, Ethel \& Claudio César CALABRESE (2019) : «La condición órfica en la narración maravillosa: tres cuentos de Perrault». Çédille, revista de estudios franceses, 16, 295-312. DOI: https://doi.org/10.25145/j.cedille.2019.17.16.18. 